\title{
Mind the gap: implementation challenges break the link between HIV/AIDS research and practice
}

\section{Cuidado com a distância: desafios na implementação rompem o elo entre pesquisa e prática em HIV/AIDS}

\author{
Atentos a la brecha: desafíos de implementación \\ rompen el vínculo entre el VIH/SIDA \\ investigación y práctica
}

Sarah MacCarthy 1

Sari Reisner ${ }^{2}$

Michael Hoffmann 3

Amaya Perez-Brumer 4

Alfonso Silva-Santisteban 5

Amy Nunn 3

Leonardo Bastos 6

Mauricio Teixeira Leite de Vasconcellos 7

Ligia Kerr 8

Francisco Inácio Bastos 9

Inês Dourado 10

\begin{abstract}
Sampling strategies such as respondent-driven sampling (RDS) and timelocation sampling (TLS) offer unique opportunities to access key populations such as men who have sex with men (MSM) and transgender women. Limited work has assessed implementation challenges of these methods. Overcoming implementation challenges can improve research quality and increase uptake of HIV services among key populations. Drawing from studies using RDS in Brazil and TLS in Peru, we summarize challenges encountered in the field and potential strategies to address them. In Brazil, study site selection, cash incentives, and seed selection challenged RDS implementation with MSM. In Peru, expansive geography, safety concerns, and time required for study participation complicated TLS implementation with MSM and transgender women. Formative research, meaningful participation of key populations across stages of research, and transparency in study design are needed to link HIVIAIDS research and practice. Addressing implementation challenges can close gaps in accessing services among those most burdened by the epidemic.
\end{abstract}

HIV; Acquired Immunodeficiency Syndrome; Sampling Studies

\footnotetext{
1 RAND Corporation,

Santa Monica, U.S.A.

2 Harvard School of Public

Health, Harvard University,

Boston, U.S.A.

3 School of Public Health

Brown University, Providence,

U.S.A.

4 Mailman School of Public

Health, Columbia University,

New York, U.S.A

5 Universidad Peruana

Cayetano Heredia, Lima

Perú.

6 Programa de Computação

Científica, Fundação Oswaldo

Cruz, Rio de Janeiro, Brasil.

${ }^{7}$ Escola Nacional de Ciências

Estatísticas, Fundação

Instituto Brasileiro de

Geografia e Estatística,

Rio de Janeiro, Brasil.

${ }^{8}$ Faculdade de Medicina

Universidade Federal da

Ceará, Fortaleza, Brasil.

${ }^{9}$ Instituto de Comunicação

e Informação Científica

e Tecnológica em Saúde,

Fundação Oswaldo Cruz

Rio de Janeiro, Brasil.

10 Instituto de Saúde Coletiva

Universidade Federal da

Bahia, Salvador, Brasil.
}

\author{
Correspondence \\ M. Hoffmann \\ School of Public Health, \\ Brown University. \\ 121 South Main Street \\ Suite 810 Providence, \\ RI 02912, U.S.A. \\ michael.tg.hoffmann@gmail. \\ com
}




\section{Introduction}

Although global HIV incidence is decreasing, key populations such as transgender people 1 and men who have sex with men (MSM) 2 remain disproportionately affected by HIV. In Latin America, for example, MSM and transgender women report higher HIV rates when compared to other groups ${ }^{3}$. Sampling strategies such as respondent-driven sampling (RDS) and time-location sampling (TLS) can improve access to critically important HIV services ${ }^{4}$. While there has been substantial debate regarding methodological challenges in sampling, particularly obtaining accurate prevalence estimates 5 , there remains minimal discussion regarding operational barriers to implementing these methods 6 . Therefore, this article presents two case studies of RDS and TLS from Brazil and Peru to suggest how future research may increase reach and uptake of HIV services among key populations.

\section{Definitions}

We briefly define RDS and TLS to inform our discussion of challenges associated with implementing these methods in real-world settings.

\section{RDS}

RDS is used when participants can act as better recruiters than researchers and when individuals in a population form social networks where almost all members are connected to each other 7 . Each participant interviewed receives a limited number of coupons to recruit other participants in the key population. It must be possible to track the chain of individuals recruited by the initial participant or "seed", to compute each individual's weight by collecting information associated with network size, and to establish a maximum number of possible recruitments.

\section{TLS}

TLS assumes that there are locations where the hard-to-reach population frequently visits and individuals outside this population do not visit as frequently ${ }^{8}$. A list of locations and times that the survey population visits is necessary, and "timelocation" pairs are selected from this list. From time-location pairs, a sample of the population can be selected.

\section{Case studies: lessons from Brazil and Peru}

The following text discusses unanticipated difficulties in RDS and TLS implementation. This report is not meant to compare in detail the differences between the two studies but to highlight issues associated with implementing these sampling strategies. Brazil and Peru were selected as they provide exemplary cases of RDS and TLS that addressed key populations on a large scale and illustrate how critical services can be delivered through research.

\section{RDS with MSM in 10 Brazilian cities}

In 2009, a cross-sectional study used RDS to estimate HIV prevalence among MSM in 10 Brazilian cities. Additional study information has been published elsewhere 9 .

Several lessons can be learned from this study's implementation. First, site selection proved challenging, since the funding agency required HIV testing and counseling to be conducted in government-sponsored health clinics despite concerns reported by MSM regarding potential breaches of privacy and confidentiality. In the future, the creation of community advisory boards could inform how best to overcome these concerns. Determining which community members to engage in formative research and community advisory boards is not without challenges, as individuals may not optimally represent respective interests of the study population; however, it is useful for opening communication channels and building partnerships between the local community and research team. Doing so can improve the researchers' ability to collect accurate, representative data, while also allowing key populations to access needed services.

Another challenge arose when using cash incentives, as it skewed the sample by recruiting a disproportionate number of low-income individuals and/or individuals engaging in sex work. While cash incentives may have the greatest chance of increasing recruitment, alternative incentives that address unique interests of the study population can be identified during formative work and may be more effective at recruiting a wider range of individuals from different socio-demographic backgrounds. For example, an ongoing RDS study of transgender women in Brazil will follow the recommendation of its community advisory boards (which includes transgender women from diverse socioeconomic backgrounds) to use beauty kits as an incentive for participation. Unlike convenience or snowball sampling, RDS faces a unique challenge, as 
participants must feel comfortable offering chosen incentives to their peers. Again, formative research is critical as it can ensure that incentives do not skew the sample and are acceptable to participant-recruiters.

A final challenge was seed selection, as not all seeds germinated or continuously attracted study participants. Lack of seed germination delayed study progression and may have limited sample diversity. To deal with such challenges, seeds should be educated on their role in recruiting participants and creating a diverse sample prior to study initiation. A list of alternates could also prevent delays if seeds do not germinate. Additionally, several strategies should be employed to recruit diverse seeds, including utilizing social media, social gatherings, and key informants. Ethnographic mapping, or the process of geographically locating persons or activities of interest through collection of in-depth, descriptive information about the key population 10 , can also ease implementation of RDS. Specifically, ethnographic mapping may benefit RDS by identifying social networks of potential seeds to ensure they are distinct and capable of germinating, to thereby link more members of the key population to care.

\section{TLS with MSM and transgender women} in Peru

A 2011 HIV surveillance study conducted in Lima, Peru compared convenience sampling (CS), TLS, and RDS sampling methods among MSM and transgender women. Complementary study information can be found elsewhere 11. Several challenges were encountered in study implementation. One primary challenge with TLS was the large geographic area of Lima, Latin America's fifth largest city with almost nine million inhabitants, which substantially increased the cost of study implementation. Moreover, since economic resources were scarce, only one mobile van unit was present at each outing, lengthening study completion time and limiting geographic reach. Again, intensive formative research can determine the best way to uniformly cover geographic areas of interest, while also minimizing costs by ensuring that targeted areas provide maximum access to key populations.

Additionally, field workers were not readily familiar with many target locations given Lima's size. Therefore, integration of personnel from the ethnographic mapping stage with the TLS field team would assist in understanding field site location and security. Doing so can minimize safety concerns by building relationships with venue owners and local community members to raise awareness of the research, create a safety network for study staff, and raise interest in services offered. Ethnographic mapping with community participation is essential to identify appropriate venue-date times and to ensure that locations still exist and are available during study implementation. Further, extending collaboration to members of the key populations, in-country researchers, counselors, and field workers with previous TLS experience can simplify the training process.

A final challenge was the amount of time required for study participation. The behavioral risk survey and pre- and post-test procedures were extensive; therefore, only 2-3 people were seen per hour, and the desired sample size for TLS was not attained during the study timeframe. While it may be tempting for researchers to collect extensive amounts of data per participant, it is important that the participant's time is valued, such that questions are asked only if data will contribute to specific questions driving the research. Doing so can ensure that research is conducted efficiently and effectively.

The challenge of accessing hard-to-reach populations in real life conditions: brief insights from Brazil

Brazil is a continental-sized country, characterized by many heterogeneities, including regional variation and social differences based on gender, ethnic and racial background, or income. These heterogeneities frequently interact and are superimposed on each other, particularly in cities and among urban residents, especially hard-toreach populations. It is not a coincidence that deep contrasts and often, contradictory findings are found in urban research, including in multicity studies and multiple-methods studies carried out in a single city. One example of the former was previously discussed by an RDS-based study in Rio de Janeiro, where structural bottlenecks, including the informal but pervasive control of deprived communities by rival criminal factions and paramilitary groups, blocked the unfolding of successive recruiting waves in many parts of the city, such as in Rocinha, one of its largest poor communities, with 150,000 residents 12 .

The same contrasts were found both within Rio de Janeiro and between Brazil's two major cities, Rio de Janeiro and São Paulo, in a recent national survey on crack cocaine. The striking contrast between the nature and dynamics of open drug scenes in Rio de Janeiro and the marked differences between Brazil's two major cities, interconnected by the most dense network of highways, bus routes, aerial shuttle etc. were 
documented in detail with the help of visual aids, detailed mapping and ethnography 13,14. Respondent-driven sampling in "real life conditions" 5 or, alternatively, time-location based studies is not immune to these deep heterogeneities.

\section{Conclusions}

While others have highlighted the methodological complexity of sampling key populations, we illustrate the importance of understanding and addressing operational challenges related to RDS and TLS in two novel case studies. These examples spanned two different countries and populations in a region with a fast growing HIV epidemic among key groups; however, both experiences underscored the importance of in-depth formative research to ensure that site selection creates a confidential space for participants to incentivize enrollment, while also allowing for systematic coverage across the desired geographic area. Meaningful collaboration with communities proved essential to successful implementation of both studies and allowed the research team to assess potential risks and harms to participants. Lastly, ethnographic mapping was a critical component to formative research in both studies to ensure diverse seed selection and appropriate venue-date times. Notably, challenges and potential solutions described may be relevant to traditional sampling methods; nonetheless, discussing them with respect to RDS and TLS remains important because they are currently the best strategies employed to access key populations and obtain representative samples.

While this article does not address in-depth the nuances of each sampling method, we have highlighted critical implementation challenges that should be further discussed by the research community to hopefully benefit from our lessons learned and increase uptake of needed services. Implementation challenges are often excluded from peer-reviewed literature, impeding researchers from sharing experiences and building on lessons learned from the field Transparency in study design write-up and obstacles encountered during implementation, including scientific and practical reasons for choices made, is needed to close the gap between research and practice.

\section{Contributors}

S. MacCarthy made substantial contributions to the conception of the work and drafting the work for important intellectual content. S. Reisner, M. Hoffmann and A. Nunn made substantial contributions to the conception of the work and revising the work for important intellectual content. A. Perez-Brumer and A. Silva-Santisteban made substantial contributions to the conception of the work with respect to Peru and revising the work for important intellectual content. L. Bastos, M. T. L. Vasconcellos, L. Kerr, F. I. Bastos and I. Dourado made substantial contributions to the conception of the work with respect to Brazil and revising the work for important intellectual content.

\section{Acknowledgments}

We appreciate the support from the Lifespan/Tufts/ Brown Center for AIDS Research and the National Institute of Allergy and Infectious Diseases (T32DA13911-12; P30AI042853). We also appreciate the support from the National STD/AIDS and Hepatitis Department of the Ministry of Health (CSV 234/07). Finally, we acknowledge the 2011 Peruvian Sentinel Surveillance Working Group, including Asociación Civil ImpactaSalud y Educación, Ministerio de Salud, U.S. Naval Medical Research Unit-6, and University of California.

\section{References}

1. Baral SD, Poteat T, Stromdahl S, Wirtz AL, Guadamuz TE, Beyrer C. Worldwide burden of HIV in transgender women: a systematic review and meta-analysis. Lancet Infect Dis 2013; 13:214-22.

2. Beyrer C, Baral SD, van Griensven F, Goodreau SM, Chariyalertsak S, Wirtz AL, et al. Global epidemiology of HIV infection in men who have sex with men. Lancet 2012; 380:367-77.

3. De Boni R, Veloso VG, Grinsztejn B. Epidemiology of HIV in Latin America and the Caribbean. Curr Opin HIV AIDS 2014; 9:192-8.

4. Magnani R, Sabin K, Saidel T, Heckathorn D. Review of sampling hard-to-reach and hidden populations for HIV surveillance. AIDS 2005; 19 Suppl 2:S67-72.

5. Salganik MJ. Commentary: respondent-driven sampling in the real world. Epidemiology 2012; 23:148-50.

6. Johnston LG, Malekinejad M, Kendall C, Iuppa IM, Rutherford GW. Implementation challenges to using respondent-driven sampling methodology for HIV biological and behavioral surveillance: field experiences in international settings. AIDS Behav 2008; 12(4 Suppl):S131-41.

7. Semaan S. Time-space sampling and respondentdriven sampling with hard-to-reach populations. Methodol Innov Online 2010; 5:60-75. 
8. Nguyen NT, Nguyen HT, Trinh HQ, Mills SJ, Detels R. Clients of female sex workers as a bridging population in Vietnam. AIDS Behav 2009; 13:881-91.

9. Kerr LR, Mota RS, Kendall C, Pinho AA, Mello MB, Guimaraes MD, et al. HIV among MSM in a large middle-income country. AIDS 2013; 27:427-35.

10. Tripathi BM, Sharma HK, Pelto PJ, Tripathi S. Ethnographic mapping of alcohol use and risk behaviors in Delhi. AIDS Behav 2010; 14 Suppl 1:S94-103.

11. Clark JL, Konda KA, Silva-Santisteban A, Peinado J, Lama JR, Kusunoki L, et al. Sampling methodologies for epidemiologic surveillance of men who have sex with men and transgender women in Latin America: an empiric comparison of convenience sampling, time space sampling, and respondent driven sampling. AIDS Behav 2014; 18:2338-48.

\section{Resumo}

Estratégias de amostragem como respondent-driven sampling (RDS) e time-location sampling (TLS) são importantes opções metodológicas para acessar populações chaves para a epidemia de HIVIAIDS como homens que fazem sexo com homens (HSH) e mulheres transexuais. Porém são poucos os estudos que avaliam desafios de implementação desses métodos. Objetivamos apresentar os principais desafios na implementação dos RDS no Brasil e TLS no Peru. No Brasil, o local da pesquisa, a seleção das sementes, e o tipo de ressarcimento foram desafios na implementação do RDSHSH. E no Peru, as questões geográficas, preocupações com segurança, e o tempo necessário para participar no estudo complicaram o TLS com HSH e mulheres transexuais. Pesquisa formativa, participação das populações chaves em todas as fases da pesquisa, e transparência no desenvolvimento do estudo são necessários para utilização prática dos resultados. Melhorar a implementação dessas pesquisas pode contribuir para aumentar o acesso aos serviços de prevenção e controle do HIVIAIDS entre aqueles que mais precisam.

HIV; Síndrome de Imunodeficiência Adquirida; Amostragem
12. Toledo L, Codeco CT, Bertoni N, Albuquerque E, Malta M, Bastos FI. Putting respondent-driven sampling on the map: insights from Rio de Janeiro, Brazil. J Acquir Immune Defic Syndr 2011; 57 Suppl 3:S136-43.

13. Mann CG, Bastos FI. A brief photo-biography of crack users from Rio de Janeiro's metropolitan area: their settings and tools. Subst Use Misuse 2015; 50:520-2.

14. Krawczyk N, Veloso Filho CL, Bastos FI. The interplay between drug-use behaviors, settings and access to care: a qualitative study exploring attitudes and experiences of crack cocaine users in Rio de Janeiro and São Paulo, Brazil. Harm Reduct J 2015; $12: 24$.

\section{Resumen}

Estrategias de muestra como respondent-driven sampling (RDS) y time-location sampling (TLS) son importantes opciones metodológicas para acceder a poblaciones claves para la epidemia de VIH/SIDA como los hombres que tienen sexo con hombres (HSH) y mujeres transexuales. No obstante, son pocos los estudios que evalúan los desafíos de implementación de esos métodos. Tenemos como objetivo presentar los principales desafios en la implementación de los RDS en Brasil y TLS en Perú. En Brasil, el lugar de la investigación, la selección de las muestras, y el tipo de compensación fueron desafíos en la implementación del RDS-HSH. Y en Perú, las cuestiones geográficas, preocupaciones con la seguridad, y el tiempo necesario para participar en el estudio complicaron el TLS con HSH y mujeres transexuales. Se trata de una investigación formativa, con participación de las poblaciones claves en todas las fases de la investigación, y transparencia en el desarrollo del estudio, todo ello necesario para la utilización práctica de los resultados. Mejorar la implementación de esas investigaciones puede contribuir a aumentar el acceso a los servicios de prevención y control del VIH/ SIDA entre aquellos que más lo necesitan.

VIH; Síndrome de Inmunodeficiencia Adquirida; Muestreo
Submitted on 25/Mar/2015

Final version resubmitted on 27/Aug/2015

Approved on 25/Nov/2015 